\title{
Educação Ambiental e Leitura: Aprendizagem Significativa
}

\author{
Maria José da Silva Bezerra'; Theóphilo Álvares cabral Beserra²
}

\begin{abstract}
Resumo: O objetivo do presente artigo é analisar o desenvolvimento da leitura de forma significativa, através do entrelaçamento com o tema educação ambiental. Trata-se de uma temática importante para a sustentabilidade do planeta, portanto, apropriado para leitura e escrita, com o objetivo de aprofundar as discussões em sala de aula. Conscientizar e incentivar ações de mudanças de atitudes em prol da questão ambiental, são estratégias de ação que podem ser adotadas ao se trabalhar com a fluência da leitura com o educando. Os resultados se mostraram importantes para uma aprendizagem mais significativa da leitura e da escrita.
\end{abstract}

Palavras chave: educação ambiental, leitura, aprendizagem significativa.

\section{Environmental Education and Reading: Meaningful Learning}

\begin{abstract}
The purpose of this paper is to analyze the development of reading significantly, by interweaving the theme environmental education. This is an important issue for the sustainability of the planet, therefore, suitable for reading and writing, in order to deepen discussions in the classroom. Raise awareness and encourage actions to changing attitudes towards environmental issue, they are action strategies that can be adopted when working with reading fluency with the student. The results were important for a more meaningful learning of reading and writing.
\end{abstract}

Keywords: environmental education, reading, meaningful learning.

\section{Introdução}

A educação ambiental influencia a aprendizagem da leitura? A leitura influencia o aprendizado da educação ambiental? Essas questões serão analisadas na perspectiva de uma aprendizagem significativa da leitura, ou seja, aquela leitura que realmente se faz necessária para aprender algo. No caso se relacionar de forma sustentável com o meio ambiente, o qual é concreto e pode ser transformado com a ação humana. Valoriza o conhecimento prévio do aluno, a partir do qual sua aprendizagem se desenvolve.

\footnotetext{
${ }^{1}$ Graduada em Licenciatura do Ensino Fundamental. Mestranda em Educação pela Anne Sullyvan University.

${ }^{2}$ Mestre em Geografia pela Universidade Federal do Ceará - UFC. E-mail: mic.beserra@ hotmail.com
} 
Como por exemplo quando o aluno chega a sala de aula, já vem com um conceito elaborado sobre um determinado assunto na sua estrutura cognitiva, o mesmo facilita o aprendizado de novos conceitos mais elaborados, modificando e aprimorando o que já sabia sobre o assunto. Aí ocorre a aprendizagem significativa.

A importância da leitura para a conscientização ambiental é tratada aqui como prioridade para os estudos desde o começo da vida escolar, visto que, a educação é algo a longo prazo. A leitura com temas ligados com a realidade do aluno proporciona motivação e interesse e, consequentemente uma aprendizagem significativa.

Esse estudo procura incentivar e conscientizar o aluno, no seu cotidiano de sala de aula, para uma questão real e urgente que diz respeito a sua convivência com o meio ambiente. Como explicitado nos Parâmetros Curriculares Nacionais, o conhecimento sobre o tema é fundamental:

No entanto, para que se possa compreender a gravidade desses problemas e vir a desenvolver valores e atitudes de respeito ao meio ambiente é necessário que, antes de tudo, se saibam quais as qualidades desse ambiente, dessa natureza que se quer defender, porque as pessoas protegem aquilo que amam e valorizam. (PCN, 1997, p.73).

Conhecendo esse ambiente, e através de leituras diversificadas, o aluno poderá adquirir atitudes de respeito ao meio ambiente, se tornando parte fundamental desse processo de mudança de hábitos, sendo multiplicador e influenciando outras pessoas.

Distribuídos em subitens, este artigo faz um breve relato sobre educação ambiental, onde é enfocado o começo da preocupação com o meio ambiente, as causas de tantos problemas ambientais, a educação escolar como ferramenta para a conscientização de um desenvolvimento sustentável.

Leitura - este subitem chama a atenção para a aprendizagem e desenvolvimento da leitura com a temática ambiental desde os primeiros anos da vida escolar, onde o educando irá formando sua personalidade ao longo do seu desenvolvimento já com essa consciência ambiental, utilizando a leitura como via de acesso a novos conhecimentos.

Aprendizagem significativa - aqui se faz uma relação da leitura com a educação ambiental de forma significativa, valorizando o conhecimento prévio do aluno, momento em que, ele possa 
Id on Line Revista Multidisciplinar e de Psicoloqia

Id on Line Multidisciplinary Journal and Psycology

refazer, aprofundar, transformar, construir novos conceitos sobre educação ambiental e ao mesmo tempo desenvolver a leitura de forma prazerosa.

As considerações finais - fazem um arremate dos assuntos tratados e incentiva a realização de novas leituras sobre essas questões tão importantes, na perspectiva que inspire e motive cada vez mais estudos a respeito desses temas, educação ambiental e leitura, para que os dois se tornem presenças constantes nas salas de aulas e em todas as disciplinas.

\title{
Educação Ambiental
}

Segundo estudos, a partir de meados dos anos 1960, os recursos naturais foram diminuindo, dando início a uma crise ecológica. A água, o ar, a destruição da camada de ozônio, entre outros, foram motivos para se iniciar uma ampla discussão sobre o meio ambiente.

O desenvolvimento sustentável ficou em evidência, já que o homem ao transformar o meio ambiente sem levar em conta os danos ecológicos e sociais, agride a natureza e causa destruição, então, para manter o equilíbrio do ambiente e a manutenção da vida faz-se necessário uma reflexão sobre o progresso tecnológico e os problemas causados por eles.

As populações com o intuito de produzir cada vez mais não se dão conta dos efeitos maléficos causados por algumas de suas criações, como afirma Morin (2012, 41), “empobreceram ao enriquecer, destruíram ao criar".

A qualidade de vida das pessoas e a preservação da natureza não foram respeitadas pelo progresso e desenvolvimento econômico. Hoje, porém, busca-se de todas as formas reverter esse quadro de destruição provocado pelo próprio homem.

\begin{abstract}
A demanda por novos recursos impôs, ao homem a necessidade de expansão territorial. Esta por sua vez, comprometeu não apenas o equilíbrio de muitos ambientes, mas a manutenção da própria vida no planeta, já que as formas de exploração aniquilaram inúmeras espécies, inclusive, vários povos ou sociedades. (FREITAS e FERREIRA - ORG, 2012, p.35).
\end{abstract}

Em alguns casos, a ganância desenfreada tem levado o homem a praticar ações insustentáveis contra o meio ambiente, só com o intuito de poder e enriquecimento. Mas, o 
planeta reage de forma lenta para que o ser humano retire o véu da ignorância e mude de atitude.

É urgente que se faça algo em prol do meio ambiente. O ser humano precisa de uma vez por todas retribuir com cuidados o que retirou da natureza. Os problemas relacionados ao clima, água, lixo, desmatamento, entre muitos outros, exigem atenção imediata.

O desafio da educação ambiental é grandioso, fazer com que o ser humano aprenda a lidar com o seu meio sem agredi-lo tanto, evitar o desgaste da natureza, já tão devastada, que a ação não fique só no discurso.

\begin{abstract}
Chegamos a um ponto da jornada humana em que as sociedades vão compreendendo que a alternativa indiscutível está entre renovar-se ou perecer. Nem resta, a tais sociedades, folga de tempo para que tomem as primeiras atitudes, pois problemas mundiais como aquecimento global, as bruscas mudanças climáticas, o desmedido crescimento demográfico com crise no abastecimento de água potável etc., cobram uma urgência nunca antes conhecida ou enfrentada pela humanidade. (MORAIS, 2004. 12).
\end{abstract}

A exploração, sem controle, dos recursos naturais, causa a degradação do meio onde o próprio homem está inserido. A partir dessa conscientização, ele busca o desenvolvimento de forma sustentável e que não agrida tanto a natureza, de modo equilibrado, gerando assim a defesa do meio ambiente e a conservação da natureza. É fundamental para o aluno que essa conscientização seja trabalhada desde o começo da vida escolar, para que num futuro próximo o meio ambiente realmente seja respeitado.

Sabe-se que a educação é um processo a longo prazo, devendo ser, portanto, implementada a questão ambiental desde a mais tenra idade, desde as primeiras leituras, deixando claro que cada ser humano tem seu tempo de aprendizagem, mas que são urgentes as medidas necessárias em todas as esferas da sociedade para esse problema mundial. E que começa muito próximo, com coisas muito simples, até mesmo um pequeno papel jogado no chão.

A preocupação em relacionar a educação com a vida do aluno - seu meio, sua comunidade - não é novidade. Ela vinha crescendo especialmente desde a década de 60 no Brasil. Exemplo disso são atividades como os "estudos do meio". Porém, a partir da década de 70, com o crescimento dos movimentos ambientalistas, passouse a adotar, explicitamente a expressão "Educação Ambiental" para qualificar iniciativas de universidades, escolas, instituições governamentais e não- 
governamentais pelos quais se busca conscientizar setores da sociedade para as questões ambientais. ( PCN, 1997, p. 26).

Apesar de ser debatida, há muito tempo, a educação ambiental, agora que parece está se tornando prioridade e, especialmente para as novas gerações ela deve ser difundida e nada mais oportuno do que na escola, nas leituras que perpassam às diversas disciplinas.

\section{A leitura com a temática ambiental}

Os recursos didáticos são importantes componentes do ambiente de aprendizagem, utilizados de forma adequada. No caso da leitura não é diferente, principalmente para adquirir conhecimento sobre o seu próprio ambiente. Através de leituras de diferentes gêneros textuais como: informativo, poema, conto, notícia e muitos outros suportes, o meio ambiente está presente, então lendo o aluno aprende como se inserir nesse desenvolvimento sustentável e participar ativamente da conservação do planeta.

A leitura é a atividade mais importante desenvolvida pela escola. Ela é uma atividade individual, ou seja, cada pessoa tem uma compreensão única do que leu. A leitura proporciona a assimilação de conhecimentos, a reflexão. O leitor procura resgatar pensamentos de quem escreveu, refletindo e construindo opiniões, sobre o que entendeu auxiliado por sua leitura do mundo.

\footnotetext{
A leitura do mundo precede a leitura da palavra, dai que a posterior leitura desta não possa prescindir da continuidade da leitura daquele. Linguagem e realidade se prendem dinamicamente. A compreensão do texto a ser alcançada por sua leitura crítica implica a percepção das relações entre o texto e o contexto. (FREIRE, 1999, 11).
}

As crianças vivem rodeadas de informações sobre leitura. Iniciam sua aprendizagem nos mais variados contextos e de várias procedências. Quando um adulto lê uma carta, um jornal, uma história, uma receita culinária, indiretamente informa-se à criança a função social da leitura. Nesse sentido a escola tem um papel importante na formação de leitores proficientes. Quando o aluno se apropria do ato de ler, ele dá significado ao que lê, 
Id on Line Revista Multidisciplinar e de Psicologia

Id on Line Multidisciplinary Journal and Psycology

interpretando e assimilando conhecimento. Nesse contexto o tema da leitura é muito importante, porque além de desenvolver a leitura em si, o tema também será compreendido, debatido, contextualizado e nada mais oportuno do que a temática ambiental ser desenvolvida na escola através da leitura. Já que, como afirma Cagliari (2010, p. 131): "Tudo o que se ensina na escola está diretamente ligado à leitura e depende dela para se manter e se desenvolver".

Nessa perspectiva a educação ambiental na escola deve começar pelo ensino da leitura desde os primeiros anos da vida escolar, conscientizando a partir do ambiente da sala de aula com a questão da conservação da limpeza e dai estender para outras áreas da escola e fora dela. O aluno deverá se conscientizar que o meio ambiente próximo e mais distante são igualmente importantes.

Portanto, além de considerar a leitura uma grande fonte de conhecimento da questão ambiental, a percepção crítica e interpretação e os conhecimentos, originando a compreensão do que foi lido. Contudo, na escola o professor precisa desenvolver atividades dinâmicas, variadas e significativas. É imprescindível que o professor se envolva nos atos de leitura, lendo também para que o aluno se espelhe nele e conheça o valor de realizar essa tarefa.

Para tornar os alunos bons leitores, para desenvolver, muito mais do que a capacidade de ler, o gosto e o compromisso com a leitura, a escola terá de motiválos internamente, pois aprender a ler (e também ler para aprender) requer esforço. Precisará fazê-los achar que a leitura é algo interessante e desafiador, algo que, conquistado plenamente, dará autonomia e independência. Precisará torná-los confiantes, condição para poderem se desafiar a " aprender fazendo". Uma prática de leitura que não desperte e cultive o desejo de ler não é uma prática pedagógica eficiente. ( PCN, 1997 : 58).

Despertando o interesse pela leitura com temas relevantes como a educação ambiental, a tarefa de ler se tornará prazerosa, sendo contextualizada e implicando em conhecimento do objeto de estudo, o meio ambiente.

Nesse ritmo de ecologização das sociedades, nunca será demasiado produzirmos textos de alerta para o campo educacional, desde que sejam nascidos de boa pesquisa e dotados da força sensibilizadora suficiente para romper certa crosta de comodismo alienado que envolve nosso campo educacional. Assim, chegamos ao ponto de nos determos propriamente sobre a interdependência entre ecologia e educação. (MORAIS, 2004, 24) 
Nas leituras realizadas na escola, não só nas aulas de português, a questão ambiental, tratada como tema transversal deve ser incluída em diversos momentos em todas as disciplinas. É interessante essa reflexão para que a educação ambiental seja apresentada reiteradas vezes e de diferentes formas, nos mais variados contextos.

Visto que o tema é fundamental e urgente para a conservação do planeta, ele deve ser inserido na educação e trabalhado em todas as disciplinas, desde os primeiros anos de vida escolar.

\title{
A aprendizagem significativa da leitura
}

Com o conhecimento prévio do aluno sobre as diversas temáticas e em especial a educação ambiental, tratada aqui, cuja assimilação é baseada na convivência do aluno com o objeto de estudo no seu cotidiano, o mesmo vai, empiricamente falando, construindo o seu saber antes mesmo de chegar à educação formal. Esse conhecimento sendo valorizado na escola vai motivá-lo cada vez mais a descobrir, aprender a desenvolver o que já sabe e "ancorar", de acordo com a teoria de Ausubel, o novo conhecimento.

\begin{abstract}
Sabe-se, também, que o conhecimento prévio é, isoladamente, a variável que mais influencia a aprendizagem. Em última análise, só se pode aprender a partir daquilo que já se conhece: David Ausubel já chamava atenção para isso em 1963. Hoje, todos reconhecem que nossa mente é conservadora, aprende-se a partir do que já se tem na nossa estrutura cognitiva. Como dizia ele, já nessa época, se se quer promover a aprendizagem significativa é preciso averiguar esse conhecimento e ensinar de acordo. ( MOREIRA. 2014, 225).
\end{abstract}

Portanto, as aulas de leitura devem ser desafiadoras e o aluno precisa está motivado para o êxito da aprendizagem, possibilitando a reflexão com significado. É fundamental que o aluno pense sobre o conteúdo estudado o qual deve ser interessante e com significado social, para que não se torne algo mecânico.

O assunto destacado neste artigo, educação ambiental e leitura combinam perfeitamente para uma aprendizagem significativa, pois ao sentir o ambiente real, perceber suas características, o aluno compreende e constrói e assim construir o seu conhecimento. 
Id on Line Revista Multidisciplinar e de Psicoloqia

Id on Line Multidisciplinary Journal and Psycology

Através da leitura ele conhece mais o ambiente e ao conhecê-lo pode transforma-lo, ou seja, os dois interagem, a leitura e o assunto abordado.

Quanto ao momento da aula significativa é imprescindível que professor e aluno dialoguem, que comuniquem o pensamento e assim a aprendizagem realmente aconteça.

Que o pensar do educador somente ganha autenticidade do pensar dos educandos, mediatizados ambos pela realidade, portanto, na intercomunicação. Por isso, o pensar daquele não pode ser um pensar para estes nem a estes impostos. Dai que não deva ser um pensar no isolamento, na torre de marfim, mas na e pela comunicação, em torno, repitamos, de uma realidade. (FREIRE, 2015, 89-90).

Essa realidade, nesse caso específico, abordado anteriormente, o seu meio ambiente, de onde o aluno já vem com o conhecimento prévio e o qual vai ajudar em novos conhecimentos que através da leitura sistemática vai possibilitar a aprendizagem significativa.

Para Ausubel, aprendizagem significativa é um processo por meio do qual uma nova informação relaciona-se com um aspecto especificamente relevante da estrutura de conhecimento do indivíduo, ou seja, este processo envolve a interação da nova informação com uma estrutura de conhecimento específica, a qual Ausubel define como conceito subsunçor, ou simplesmente subsunçor, existente na estrutura cognitiva do indivíduo. A aprendizagem significativa ocorre quando a nova informação ancora-se em conceitos ou proposições relevantes, preexistentes na estrutura cognitiva do aprendiz. Ausubel vê o armazenamento de informações no cérebro humano como sendo organizado, formando uma hierarquia conceitual, na qual elementos mais específicos de conhecimentos são ligados (e assimilados) a conceitos mais gerais, mais inclusivos. Estrutura cognitiva significa, portanto, uma estrutura hierárquica de conceitos que são representações de experiências sensoriais do indivíduo. (MOREIRA, 2014, 161).

No caso do ensino da leitura o aprendiz se pautará no tema do texto, e o conhecimento já existente sobre o assunto na sua estrutura cognitiva facilitará o aperfeiçoamento de conceitos ou a elaboração de novos conceitos. Portanto o assunto específico da questão ambiental será compreendido e interpretado com facilidade, consolidando assim, a assimilação e aprendizagem do conteúdo. 
Id on Line Revista Multidisciplinar e de Psicoloqia

Id on Line Multidisciplinary Journal and Psycology

\section{Considerações finais}

Os relatos aqui desenvolvidos têm a intenção de construir significado ao ensino da leitura com temas relevantes como o abordado no decorrer do trabalho, educação ambiental, que pode contribuir para a aprendizagem significativa e ao mesmo tempo favorecer a consciência ambiental do aluno, o qual deve aprender a respeitar e transformar as atitudes em prol do meio ambiente.

Constatar que a educação ambiental é um assunto instigante que contribui na aprendizagem da leitura e ao mesmo tempo a leitura, sem sombra de dúvida, permite o conhecimento sistemático do leque de opções sobre o tema ambiental é altamente satisfatório. Impulsionar o conhecimento, a reflexão sobre os problemas ambientais com criticidade faz parte da função social da leitura.

A educação ambiental facilita o interesse do educando nas aulas onde a leitura de textos significativos, que trata da realidade, que instruem que orientam, enfim que ensinam a pensar é constante. Então leitura, aprendizagem significativa, educação ambiental são peças importantes nessa engrenagem do saber que produz o pensar, o fazer, o transformar. Que essa reflexão sirva de incentivo para outros estudos, outras leituras.

\section{Referências}

CAGLIARI, L.C. Alfabetização e Linguística. São Paulo: Scipione, 2009.

FREIRE, P. A importância do Ato de Ler: em três artigos que se completam. São Paulo: Cortez, 1999.

Pedagogia do Oprimido. 59. Ed. Rio de Janeiro: Paz e Terra, 2015.

FREITAS, E. S. M. e FERREIRA, A.A. (org.). Meio Ambiente em Cena. Belo Horizonte: RHJ, 2012.

MORAIS, R. Educação, mídia e meio ambiente. Campinas, SP: Alínea, 2004.

MOREIRA, M. A. Teorias da Aprendizagem. São Paulo: E. P. U., 2014.

MORIN, E. Os sete saberes necessários à educação do futuro. São Paulo: Cortez: 2012. 
PARÂMETROS CURRICULARES NACIONAIS. Língua Portuguesa: Brasília: Ministério da Educação e Desporto, 1997.

Meio Ambiente e Saúde. Brasília: Ministério da Educação e Desporto, 1997.

\section{Como citar este artigo (Formato ABNT):}

BEZERRA, M.J.S.; CABRAL, T.M.A. Educação ambiental e leitura: aprendizagem significativa. Id on Line Revista Multidisciplinar e de Psicologia, Set-Out de 2016, vol.10, n.31, Supl 2, p. 330-339. ISSN 1981-1179.

Recebido: 05/09/2016

Aceito: 18/09/2016 